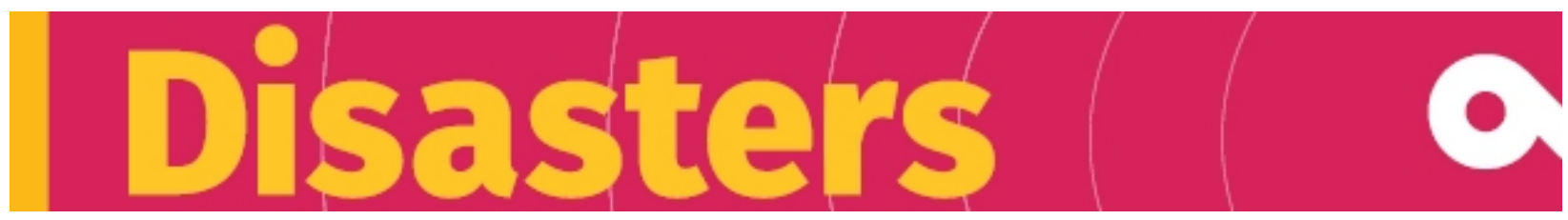

Academic publishing in disaster risk reduction: past, present, and future

\begin{tabular}{|r|l|}
\hline Journal: & Disasters Journal \\
\hline Manuscript ID & DISA-Oct-19-2818.R1 \\
\hline Manuscript Type: & Original Article \\
\hline Keywords: & Disaster risk reduction, Academic publishing, Journals, Peer review \\
\hline
\end{tabular}

SCHOLARONE ${ }^{m}$

Manuscripts 


\title{
Academic publishing in disaster risk reduction: past, present, and future
}

\begin{abstract}
Nowadays there are approximately 80 Anglophone journals that deal primarily with disaster risk reduction (DRR) and allied fields. This large array signals a sustained, if uneven, growth in DRR scholarship but also competition between the offerings of different publishers and institutions. The purpose of this article is first to summarise the development of academic publishing on DRR from its early beginnings to the present day. The paper then evaluates the current state of publishing in this field and discusses possible future trends. Next, it identifies some possible opportunities, challenges, expectations, and commitments for journal editors both within DRR and academia more broadly, including those that refer to changes in the use of terminology, the relentless increase in the number of papers submitted, the expansion and dangers of predatory journals, different peer review models, open access versus paywalls, citations and bibliography metrics, academic social networks, and copyright and distribution issues.
\end{abstract}

Keywords: disaster risk reduction, academic publishing, journals, peer review

\section{Introduction}

On 6th March 1665 in London, the theologian, philosopher, and diplomat Henry Oldenburg published the first volume of Philosophical Transactions, the journal of the Royal Society. This was the beginning of a process of scientific and academic publication that has lasted, with remarkably few alterations, until the present day. Phil. Trans., as it became known, rapidly established the format of the scientific paper: title, abstract, introduction, literature review, methodology, results, conclusions, and list of references. It has proved to be an enduring vehicle for the presentation of scholarly research and debate. However, since the establishment of modern scholarship during the Enlightenment (or perhaps much earlier in the case of China), there has seldom, if ever, been a time of greater change than at present.

The purpose of this article is fourfold: (a) to summarise the development of academic publishing on risks, disasters, and emergencies from its early beginnings to the present day; (b) to evaluate the current state of publishing in this field; (c) to discuss possible future trends; and (d) to discuss some possible opportunities, challenges, expectations and commitments for editors in 
the disaster risk reduction (DRR) field. We consider the field in terms of multiple dimensions that include the prevention of hazards, the mitigation of vulnerability, the enhancement of people's capacities and the study of all of these. In order to limit our analysis to manageable proportions, we focus our attention on peer-reviewed journal publishing, rather than books, reports, monographs, and the so-called "grey literature". These publishing media are interesting and important and they merit further consideration in their own right, but to be concise we limit our observations on them to their interface with journal publishing. With the exception of two significant titles in Spanish, we focus on journals that publish in the English language. We recognise that this might be construed as a bias. However, it reflects the position of English as the dominant language in academic publishing worldwide, its role as a lingua franca, and its impact on how ideas are shaped in disaster risk reduction and cognate fields of study.

We are editors or on the editorial boards of a diverse range of journals in the disasters field, representing views from around the world. Although we do not claim to represent all possible views of academic publishing in DRR, we believe our collective experience qualifies us to make general statements about trends and developments in the field, and about the current state of publishing therein. Our account begins by taking stock of the current situation in the publication of peer reviewed journals that deal with DRR, emergencies, crisis management, the assessment, analysis, and management of risk, and kindred fields.

\section{A brief resumé of DRR publishing}

Currently, about 80 Anglophone journals deal primarily with disaster risk reduction and allied fields. Two others in Spanish play an influential role in international scholarship in this field, while most journals in other languages have limited readership outside their linguistic field of influence. About ten journals have ceased publication, but these are balanced by the persistent tendency to found new titles. As their scope varies from plenary coverage to limited issues, it is difficult to classify journals by content. For example, the Journal of Extreme Events (published by World Scientific) has a very wide brief, while the International Journal of Disaster Resilience in the Built Environment (Emerald) has a much more restricted focus. In terms of content, the main divisions are as follows: disaster risk reduction, emergency response, humanitarian practice, emergency medicine and health, natural hazards, risk analysis, management, mass communication, business continuity, and resilience. Papers in all of these fields are also published in hundreds of journals that have purviews that do not explicitly focus 
on these issues. For example, Geomorphology, Geoforum and Applied Geography (Elsevier) are plenary journals of geography that include a minority of papers on aspects of disaster risk reduction. Foundational papers on hazards and disasters have also appeared in the Journal of Hydrology (Elsevier) and Human Organization (published by the Society for Applied Anthropology).

In terms of publishers, the field is dominated by large, multinational corporations, namely Elsevier, Springer, Taylor \& Francis, Wiley-Blackwell, and Palgrave Macmillan. There are smaller commercial publishers, such as Emerald (Bingley, UK), InderScience (Geneva), Henry Stewart (London, UK, and Birmingham, Alabama), and Weston Medical Publishing LLC (Weston, Massachusetts). Some journals are published by societies. These include the Earthquake Engineering Research Institute (which publishes Earthquake Spectra), the Seismological Society of America (Bulletin of the Seismological Society of America), the European Geophysical Union (Natural Hazards and Earth System Sciences), the International Sociological Association's Research Committee on the Sociology of Disasters (International Journal of Mass Emergencies and Disasters), and the Southern Africa Society for Disaster Reduction (Jámbà: Journal of Disaster Risk Studies). There are also journals published by university research centres (e.g. the Australasian Journal of Disaster and Trauma Studies from Massey University's Joint Centre for Disaster Research) and those issued by networks of researchers and practitioners (Desastres y Sociedad, published by La Red de Estudios Sociales en Prevención de Desastres en América Latina). Finally, there are journals that are managed by private companies that, rather controversially, appear on the website "Beall's list of predatory journal and publishers". These so-called "predatory" journals are alleged to charge significant fees to publish manuscripts through a speedy process that is claimed to not involve adequate control of quality or integrity (Beall, 2012).

This large array of journals and publishers favours different approaches to peer review, which we can regard as the bottom-line of academic publishing. Publications grounded in the traditions of earth and engineering sciences mostly rely on a single-blind review process, in which the reviewers know the identity of the author or authors of the paper they are reviewing, but the authors cannot identify reviewers. Conversely, social science journals largely use a double-blind review process, in which neither an author nor a reviewer knows the identity of the other. New approaches are also being developed, notably the interactive public peer review 
fostered by Natural Hazards and Earth System Sciences. All these models have been criticized for being biased for one reason or another and all seem to have been associated with some forms of manipulation that ultimately threaten the reputation of the journals and academic publishing at large (Weller, 2001). An example of this is where authors take advantage of loopholes in the computer platforms used to handle the manuscripts in order to review their own papers (Ferguson et al., 2014). Issues associated with peer-reviewing are not unique to disaster studies. However, scholars researching disasters must navigate these different traditions and approaches to academic publishing, which can be challenging and frustrating.

Publication rates vary considerably between serials. The smallest may publish only three to six papers per issue, with two to four issues a year (e.g. International Journal of Mass Emergencies and Disasters and Risk, Hazards, \& Public Policy). The largest are likely to have 1,000 to 2,000 manuscripts in progress (e.g. Natural Hazards and International Journal of Disaster Risk Reduction). Acceptance rates are also quite variable. The most selective journals reject between two thirds and 90 per cent of submissions, either before review or on the basis of negative reports from referees (e.g. Disasters and Disaster Prevention and Management). The so-called predatory publishers have been accused of accepting articles without adequate peer review, providing that the authors pay substantial publication fees (Beall, 2012; Eriksson and Helgesson, 2017).

\section{The birth and development of DRR journals}

Books and reports on disasters have been issued since the start of field endeavours by the nascent scientific societies. Thus, the Royal Societies of London and Naples enquired into the southern Italian earthquakes of 1783 and 1857 and the Smithsonian Institution and the Dutch Government sent investigators to the eruption of Krakatau in 1883. They all published voluminous reports and articles in journals such as Philosophical Transactions and Nature (e.g. Hamilton, 1783; Mallet, 1862; Verbeek, 1886). Continuity in academic work on disasters perhaps began in 1920 with the publication of Samuel Henry Prince's study of the Halifax ship explosion of 1917, entitled Catastrophe and Social Change (Prince, 1920). In the 1930s and 1940s, disaster scholarship diversified with, for example, foundational pieces published by the geographer Gilbert White $(1936,1945)$ and the sociologist Lowell Juilliard Carr (1932). In the 1950s, series of reports on disasters were issued by the US National Opinion Research Centre, based at the University of Chicago, and the US National Academy of Sciences-National 
Research Council, based in Washington, DC. However, no journals were dedicated to disasters.

In 1975, a group of academics and humanitarian specialists (known informally as the London Technical Group) decided to found Disasters, a journal that would bring the fruits of rigorous research to front-line humanitarian and emergency response organisations. With the help of the publisher Robert Maxwell, Disasters first came out in 1977 under the imprint of Pergamon Press (Wisner, 2017; Davis, 2019). At the same time in the United States, sociologists at the Disaster Research Center, then based at Ohio State University, founded a home-grown journal entitled Mass Emergencies. It lasted for four volumes, 1975-79, but after a hiatus of nearly four years it was revived as the International Journal of Mass Emergencies and Disasters, an early example of desktop publishing (i.e., work produced using a home computer). Meanwhile, the International Society for Natural Hazards came into being and in 1988 the Dutch publisher Kluwer began Natural Hazards. The society faded away and Kluwer was taken over by the German multi-national Springer (formerly Springer-Verlag), but the journal grew to be one of the largest in its field.

Other journals were to follow. In some instances this has involved direct competition, for example between the International Journal of Emergency Management (InderScience) and the Journal of Emergency Management (Weston Medical), as well as the International Journal of Emergency Services (Emerald). There are also journals that have a regional focus (but perhaps global content), such as Disaster Advances (Indian subcontinent), Jámbà: Journal of Disaster Risk Studies (Africa), Australasian Journal of Disaster and Trauma Studies (Australasia and the Pacific), and Revista de Estudios Latinoamericanos sobre Reducción del Riesgo de Desastres (Latin America). At the other end of the spectrum, recent arrivals include serials, such as Resilience and the Journal of Extreme Events, which have a very loosely defined scope and aim to take advantage of what are currently popular ways of looking at events and phenomena.

Journals that have ceased publication have done so largely because of lack of commitment by publishers and editors, and certainly not because of lack of author potential or opportunities to attract a readership. For example, neither Emergency Management Review (Emergency Planning Society) nor Planet@Risk (Global Risk Forum Davos) were adequately supported so that they could survive and grow after the initial burst of activity when they were launched. The 
hardest part of establishing a journal is not its inauguration but inducing it to grow until it reaches a critical mass that will ensure its sustainability in terms of authors, readers, and the editorial and publishing support it requires. Overall, the development of the field in terms of research journals has so far occupied less than half a century, but it has been characterised by sustainect if unever growth, competition between the offerings of different publishers and institutions, rapid response to changes in fashions and terminology, and relentless increases in the numbers of papers submitted. For example, submissions to Disaster Prevention and Management increased from 98 in 2011 to more than 400 in 2018. Meanwhile, submission to the International Journal of Disaster Risk Reduction grew from a handful in mid-2012, the year it was launched, to 1,543 in 2019.

The last of these phenomena reflects two developments. The first is that disaster studies have grown to be a self-sustaining, transdisciplinary field with academic and professional leanings. It is a subject that covers dozens of disciplines and professions (Alexander, 2013), and it has gathered together thousands of scholars and practitioners. The second is that the "publish or perish" model of academic life has disseminated all over the world (Altbach, 2013). It has a particular emphasis on publishing in English and in specific journals that are endorsed by universities and research institutes. In this respect, it is possible that the most concerted motivation of academic publishing, although certainly not the most idealistic one, is for personnel reasons: to gain a post, a promotion, or job security by demonstrating to colleagues that one is a prolific scholar.

\section{Challenges and developments: Our editorial viewpoint}

Seldom, if ever, is the founding of a new journal in this field supported by an assessment of need among the academic community. This is surprising, in that a report by a task force convened by a major publisher found that disaster science (as the team defined it) represented only 0.22 per cent of scholarly output around the world (Elsevier Project Team 2017, p. 39). Hence, the best rationale for a new journal is that it be able to compete successfully with existing serial publications which cover the same material. What "compete successfully" means differs amongst the parties. Most commercial publishers and many societies rely on selling journals for income. They seek success through profitability, while editors may look for prominence in their fields and authors are typically hoping for rapid, successful publication and high rates of citation. It is difficult to assess whether the field is in a steady state regarding the number of 
journals, although there is no doubt that it is expanding relentlessly in terms of the number of papers submitted for publication.

One of the leading debates in journal publishing at the moment concerns open access. In brief, the paywalls that constrict free access to journals have been contested and a new model of open access is demanded (Schiltz, 2018). The situation is complex. Commercial publishers have gained handsome profits by limiting access to readers who pay fees. However, learned societies, for example, derive vital income streams from such revenue. Publishing is easier and more flexible than ever before, but it is not free of charge. 'Hybrid' access models involve a paywall and the granting of 'gold' open access to authors, or institutions, that pay a publication fee. This has a certain element of paying twice for the same service, a process called 'double dipping'. Paywalls tend to affect institutions more adversely in less wealthy countries. The library of a major research university in somewhere like the United States may purchase bulk subscriptions to the majority of the 30,000 journals that currently exist, but the most well-endowed Indian university subscribes to 16,500 , and in many African universities there are even fewer journal subscriptions. The University of Indonesia subscribes to 1,040 journals. This is, of course, an issue that affects all scholarship and it certainly thwarts the dissemination of useful knowledge that may help to reduce the impact of disasters. Such a situation is ironic, given that disaster studies urgently requires knowledge and information to be disseminated to the world's poorest, most vulnerable, and most marginalised communities.

The imperative to gain visibility for one's research and publications has favoured the emergence of academic social networks such as Academia and ResearchGate. There are also cognate citation tools such as Mendeley and Zotero that offer social networking functions. These online platforms allow authors to upload accepted but pre-formatted versions of their manuscripts (as permitted under most copyright agreements) so as to make them accessible to anyone who has registered. They also provide an opportunity for open review of and comments on published works, sometimes leading to the retraction of articles, as demonstrated by the widely-publicised Obokata et al. (2014) case, in which a Japanese biologist was accused of having manipulated images that supported results from cell experiments. Reach and visibility depend on the network of researchers and how many colleagues they have connected with. For traditional academic publishers, these social networks are both a challenge and an opportunity. On the one hand, they directly threaten revenues. On the other hand, they can indirectly boost citations of the 
articles published. It appears that this is why Elsevier purchased Mendeley in 2013 (Shaw, 2013). Although they often face legal battles with traditional publishers, unlike 'pirate websites' such as Sci-Hub, academic social networks are generally legal. The 'pirate' sites provide free access to hundreds of thousands of research articles and books in their published format, which further complicates the academic publishing landscape.

There are undoubtedly inequities in the ways that authors, reviewers, and editors provide their labour for free, while private companies reap the financial rewards. Many academics have jobs with regular salaries at their institutions, which should mean that journal-related work is part of their remit. A growing proportion of scholars consists of people who are on short-term contracts or in adjunct positions where they are paid mainly for teaching duties and are often poorly remunerated. Their work as authors, reviewers, or editors will not be recognised as part of their duties. Aside from the innumerable hours put in during holidays, evenings, and weekends by academics with regular jobs, those bouncing from contract to contract have little time in which to build up their publishing, reviewing, or editing profiles. Thus, they may be working entirely for free in a profit-making environment.

One response to this predicament is the rise of journals published independently by academic institutions or societies; for example, Jámbà: Journal of Disaster Risk Studies, Australasian Journal of Disaster and Trauma Studies, and Revista de Estudios Latinoamericanos sobre Reducción del Riesgo de Desastres. This entails either having volunteer copy and layout editors, who do all tasks manually and correspond via individual emails rather than automated systems, or having generous sponsors (as is the case of Jámbà, which is financially supported by the South African National Disaster Management Centre, and the Australasian Journal of Disaster and Trauma Studies, which is supported by Massey University). There are also journals published by commercial publishers that have partnered with professional societies to cover the cost of open access publication. For example, the International Journal of Disaster Risk Science is supported by the China Association for Science and Technology, Geoenvironmental Disasters is sponsored by the International Consortium on Geo-Disaster Reduction, and the Journal of International Humanitarian Action is associated with the Network on Humanitarian Action. Most of these initiatives are still relatively new. Hence, the sustainability of this model has yet to be confirmed. Meanwhile, editors and reviewers may or may not be given credit for their work by their institutions. Recognition may feed into promotion, merit raises may be added 
to salaries, or employment may be confirmed, but more often those involved see the work as a hobby sustained by effort expended entirely within their own leisure time. The degree of recognition that they receive for it from their institutions is highly variable.

Another source of inequity concerns the popularity of bibliometric measures. Most of these are based on notional measures of impact derived by counting citation rates. Typically, private companies control the agenda, determine the algorithms, and set the standards. The most widely used and well-known measure is the Thompson-Reuters impact factor (IF). Many governments and institutions demand that publications be in journals with an impact factor that exceeds a certain threshold value. This can lead to a situation in which metrics control the agenda, rather than giving space to other forms of quality assessment (Wilsdon et al., 2015). Many opponents of bibliometry argue that it is thoroughly unscientific (Moustafa, 2015). It is indeed paradoxical that scientists who demand high standards of accuracy and objectivity from their own work, and that of their peers, are willing to accept flawed models of impact assessment with hardly a murmur of protest. As impact factors are only assigned to journals which have been in regular publication for some time, new journals are started at a disadvantage. Meanwhile, established journals can consolidate their position as leading serials in their field.

An additional concern related to indexing and the use of bibliometric measures is the increasing trend of many national research evaluation systems to rely on quantitative indicators to gauge the performance of researchers. This has led to quickly-increasing 'publishing and citation inflation'. Career progression and funding depend on these metrics, affecting, if not modifying, what, how, and why authors publish. This has greatest impact on young scholars and those without permanent positions. While the efficacy of such evaluation systems is still largely unknown, it has already produced evident changes of behaviour amongst authors (Baccini et al, 2019). Deceitful methods to increase the number of publications and citations (e.g., salami slicing, crony citations, and citation clubs) are distorting individual and overall metrics (Abraham, 2000; Baccini et al., 2019). Such strategies affect all scientific fields, including disaster risk reduction. One initiative seeking to overcome such problems is the San Francisco Declaration on Research Assessment (DORA; https://sfdora.org) for which the first numbered clause recommends "Do not use journal-based metrics, such as Journal Impact Factors, as a surrogate measure of the quality of individual research articles, to assess an individual scientist's contributions, or in hiring, promotion, or funding decisions". 
The combined hegemony of the English language and the Anglophone traditions of international academic publishing can marginalise scholars whose native language is not English (Canagarajah, 2002). They face three major challenges. First, in many branches of the engineering, medical, and social sciences, articles are expected to follow standardised formats structured around an introduction, a review of the literature, description of methods, presentation of findings, discussion, and conclusions (i.e., the $17^{\text {th }}$ century Philosophical Transactions model described earlier in this article). In fact, some journal websites explicitly state that manuscripts to be submitted are required to conform to such a format. This excludes other traditions of academic writing. It is one of the reasons why many social scientists, who are used to structuring their articles in a very different way struggle to gain acceptance in Anglophone journals (Canagarajah, 2002). Second, for non-Anglophone scholars, publishing in English also means filtering their ideas through translation which may entail losing the essence of their argument in order to fit it into Anglophone concepts and frameworks. In the worst case, these scholars have to use alien concepts and terminology in order to increase the potential for citation of their work. Third, non-native speakers of English often have to rely on the very expensive services of translators or copy editors, many of whom are associated with commercial publishers. If such costs are acceptable for scholars from wealthy institutions, they may be unsustainable for researchers based in less affluent countries. Furthermore, non-native speakers of English are often at the mercy of native English-speaking peer reviewers, who are often harsh in their treatment of errors of grammar, syntax, and usage. Such reviewers may discredit a manuscript on linguistic grounds rather than on its scholarly contribution to knowledge.

Over the last century, and particularly since the Second World War, disaster studies has become very international. It is widely accepted that countries and regions have much to learn from other parts of the world concerning how to reduce the risk of, prepare for, manage, and recover from emergencies and calamities. Moreover, as disasters are ubiquitous, the field is especially polyglot. The growing body of academic literature has clearly shown that there are similar phenomena, problems, dilemmas, techniques, and theoretical issues in many different countries and settings. Some claim that the hegemony of English is probably necessary in order to ensure that the field has an adequate lingua franca for the exchange of ideas (Faber 2010). Much needs to be done to extend the sensitivity of scholars to problems encountered and solutions developed 
in cultural settings that are not their own (IFRC 2014).

\section{What does the future hold?}

At the time of writing this article, the future of academic publishing in general is far from clear. Even with the massive upheaval to science, scholarship, and society of the digital revolution, the models of article structure and peer review have proved to be remarkably robust. This might be more the product of inertia than any especially positive outcomes obtained from the dominant model. Some significant changes are evident, such as graphical abstracts, summary highlights given in bullet-point phrases, hyperlinks to supplemental material such as supporting video clips, demand for all raw data to be accessible to the readers of the paper, and a freely accessible online review process in which the journal's website publishes the article along with the reviews, readers' comments, authors' responses to the reviews, and (if the paper is accepted) the final work.

For the most part, printed journals are on the way out. Digital publication offers massive flexibility which can be seen in the new elements mentioned here. First, digitalisation eschews the page budget that so constrained the relationship between cost and size for printed journals. Second, it allows creative use of colour and hyperlinks, as well as the integration of articles with external or multimedia material. Hyperlinking to web-based material and the use of digital object identifier (DOI) data have revolutionised the way we read, although they have also introduced the frustration of continually clicking through to broken links or to websites that have been taken over by spam, viruses, and non-academic material. Third, digital publication allows 'accepted' and 'in-press' articles to be uploaded on the publisher's web platform shortly after acceptance, thus satisfying the increasing appetite of authors and their host institutions for the speedy dissemination of research findings.

An example of a useful outcome is the 'virtual special issue'. ${ }^{i}$ Whereas papers on a theme published in a printed volume must be collected and must remain physically together, journals are making use of online publishing by grouping relevant papers, even if they were not solicited as components of a special issue. If, for example, Jamaica is struck by a major earthquake or hurricane, merely by hyperlinking, a journal can quickly publish a virtual special issue that groups together all papers it has published about vulnerability and impacts in Jamaica. Similarly, at the end of the year, the journal can group by hyperlinking a virtual special issue 
of the editor's selection or of papers that have received awards. Along the same line, digital publication facilitates the gathering of ad-hoc original special issues in response to a particular demand.

These approaches have significant positive aspects. Publishers are no longer bound by yearly page budgets and word counts, nor are they constrained by printing costs to limit or exclude the use of colour or multimedia. The negative side is exemplified by the advantage given to scholars who can afford sophisticated electronic devices and fast, cheap internet connections. In addition, present-day growth appears unsustainable, as there are too many articles and too few editors and reviewers. Nor is there time to read enough of the published work. The trend towards interdisciplinarity calls into question the expertise of referees and editors who are asked to judge the content and quality of articles submitted for publication, as a work can have a very broad remit, which is a problem that challenges anyone who lacks a basic grounding in part of the field covered by the research.

In terms of citation and depth of scholarship, the new material on disaster risk reduction that is being published on an almost daily basis by academic journals tends to favour recent articles at the expense of older pioneering material. Neophilia abounds in modern academic scholarship and it is often vigorously promoted under the mistaken assumption that science advances in a linear manner that tends to assimilate or cancel out the achievements of the past. In consequence, in disaster studies there is an enduring tendency to 'reinvent the wheel', or in other words to repeat work that was carried out a long time ago because the modern scholar is not sufficiently aware of the roots of the subject (Wisner et al., 2015). This is partly because the leading scholars in the field have not defined a core curriculum that answers the question "what should an academic specialist in disaster studies have read in order to have an adequate basic understanding of the subject?" (Alexander, 2017). Many of the milestone papers, reports, and books in the field are downloadable, but access to some may be limited by paywalls and a need to pay subscriptions. Sadly, there is no central repository of essential reading.

In practical terms, much has been done to speed up publication. On-line submission now predominates. In fact, a minority of journals require authors to prepare manuscripts in near camera-ready copy that the submissions software transforms into a facsimile published work. The solicitation of peer review is similarly automated. Natural Hazards and Earth System 
Sciences has moved peer review into the public domain by enabling it to be conducted online in open access format. Copy-editing and typesetting are now both 'virtual' activities aided by machine learning and artificial intelligence. Volume, issue, and page numbers are beginning to disappear as articles are regarded more and more as free-standing pieces of scholarship identified by reference numbers and the unique universal locator or DOI. Meanwhile, research is taking place into how to achieve further transformations of the traditional journal article and the processes that extend from submission to final publication (Zudilova-Seinstra, 2013). The pace of publication has accelerated enormously, but has this occurred at the expense of quality control?

For scholars, the key to success has become the ability to publish and be cited. In this, there is a risk that quantity will take the place of quality (Wilsdon et al., 2015; Benedictus and Miedema, 2016). In his last, posthumously published book, Stephen Hawking (2018) estimated that ten papers will be published every second if the growth in academic publishing continues at its current pace, raising the question of who will have the time to read them. Because the mass media may pick up on a story or a paper may be debated on social media, publishers are stimulated to publish controversial papers and dramatise results. Some journal websites prominently display the number of clicks and downloads, which creates a self-reinforcing system. People click on, download, and cite an article (with or without reading it) because it is listed by the journal as the most highly cited or most frequently downloaded paper, which adds to the paper's metrics and keeps it listed prominently. Google Scholar mainly lists search results by citations, which assumes, perhaps wrongly, that a highly cited paper must necessarily be worth citing. Yet, the significant number of articles that remain uncited are not necessarily of poor quality (van Noorden, 2017). This begs the question of who assesses intellectual quality and if anyone really has the right to do so. Subjective quality assessments can become selfreinforcing. Moreover, one suspects that evaluators prefer papers that resemble the ones they themselves would write.

\section{Conclusions}

Overall, we welcome the diversity, creativity, and opportunity which new forms of publication and approaches to the process have given us. We are concerned that the profit-seeking models, and those that exalt metrics, heap further disadvantage upon those who are already short- 
changed by publishing. The same risk can occur as a result of the hegemony of Anglophone academic traditions. There is a risk that this state of affairs will exploit the labour of those who can least afford to provide it. It may end up burying the solid scholarship that founded the DRR field, a body of knowledge that is rich in insights that are all too easily forgotten and which have wide applicability to other fields such as climate change, resilience thinking, development, and sustainability science.

Rather than identifying and praising scholarship, the current means of assessment may cause it to degenerate as a result of the pursuit of metrics that have little inherent meaning. Our experience also suggests that quality control of the whole publication process - by authors, editors, production teams, and publishers - is vital to the success of any journal and its ability to carry important research. This will always be a labour intensive process, but sloppy scholarship and inadequate attention to the quality of procedures and products are not acceptable routes to the future of our field.

Finding solutions that genuinely improve the situation without causing more problems is the current challenge, and one that has so far proven to be particularly intractable. We respect and are encouraged by free and critical discussions that have embraced topics such as open access, predatory publication, bias, publishing ethics, and sexism and nepotism in peer review. Ironically, these matters are often served up in the most interesting ways when the debate is published in peer-reviewed papers. Initiatives such as 'Retraction Watch' monitor journals, while many journals are open to letters, responses, and corrections, which is exactly how science should operate. We are discouraged by self-appointed elites which control journals as if they were fiefdoms, by self-published papers that represent inadequate scholarship, by the occasional refusal to acknowledge concerns that are meticulously documented, and by abuses of power when early career researchers or others rightly call into question unethical practices.

One of the great risks of modern academic publishing is that the rush into (digital) print and the heavy emphasis on quantity over quality will lead to a general deterioration of scholarship. We should all examine our own practices in terms of how equitable and ethically justifiable they are. We need the courage to identify and address ad hominem attacks, blatant re-inventions, degradation of the peer-review process, crass self-referencing, manipulation of citation indices, 
and disregard for basic critical processes, among other threats to the mechanisms of science. In large measure, the future of academic publishing is reflected in the choices we make now.

Scholarly publishing of articles in the field of disaster risk reduction faces a double challenge. First, the field is changing rapidly as society itself evolves and mutates, natural and other hazards produce various forms and magnitudes of disaster, and vulnerabilities to impacts generally increases in many ways. In order to propose solutions to urgent problems, research must rise to the challenge of recognising and interpreting these phenomena. Second, academic publishing is in a phase of rapid change as the digital revolution opens up new possibilities and threatens to radically change the format of publication for the first time since the mid-17th century. The sociologist Enrico L. Quarantelli saw this revolution as a development every bit as important as the invention of printing. In a foundational paper (Quarantelli, 1997), he noted that for every predictable consequence of the digital revolution there would be unpredictable consequences, as technology both does what its designers expect and what they have not anticipated. This represents both an opportunity for greater creativity in DRR scholarship and a risk that standards will slip and vital research will be lost to a wider audience. These are the challenges we face as academics who study disasters.

\section{References}

Abraham, P. (2000) 'Duplicate and salami publications'. Journal of Postgraduate Medicine. 46(2). pp. 67-69.

Alexander, D.E. (2013) 'Approaches to emergency management teaching at the master's level'. Journal of Emergency Management. 11(1). pp. 59-72.

Alexander, D. (2017) What is essential reading in disaster studies? http://emergencyplanning.blogspot.com/2017/02/what-is-essential-reading-in-disaster.html (last accessed on 4 October 2019).

Altbach, P.G. (2013) The International Imperative in Higher Education. Sense Publishers, Rotterdam.

Baccini, A., G. De Nicolao, and E. Petrovich (2019) 'Citation gaming induced by bibliometric evaluation: a country-level comparative analysis'. PLoS ONE. 14(9). pp. e0221212. https://doi.org/10.1371/journal.pone.0221212 (last accessed on 4 October 2019)

Beall, J. (2012) 'Predatory publishers are corrupting open access'. Nature. 489(7415). p. 179. 
Benedictus R., and F. Miedema (2016) 'Fewer numbers, better science'. Nature. 538(7626). pp. 453-455.

Canagarajah, A.S. (2002) A Geopolitics of Academic Writing. University of Pittsburgh Press, Pittsburgh.

Carr, L.J. (1932) 'Disaster and the sequence-pattern concept of social change.' American Journal of Sociology. 38(2). pp. 207-218.

Davis, I. (2019) 'Reflections on 40 years of Disasters'. Disasters. 43(S1). pp. S61-S82.

Elsevier Project Team (2017) A Global Outlook on Disaster Science. Elsevier, Amsterdam.

Eriksson, S., and G. Helgesson (2017) 'The false academy: predatory publishing in science and bioethics'. Medicine, Health Care and Philosophy. 20(2). pp. 163-170.

Faber, P. (2010) 'English as an academic lingua franca'. Revista Alicantina de Estudios Ingleses. 23(1). pp. 19-32.

Ferguson, C., A. Marcus, and I. Oransky (2014) 'The peer-review scam'. Nature. 515(7528). pp. 480-482.

Hawking, S. (2018) Brief Answers to the Big Questions. John Murray Press, London.

Henderson, W. (1783) 'An account of the earthquake which happened in Italy, from February to May 1783'. Philosophical Transactions. 73. pp. 169-208.

IFRC (2014) World Disasters Report: Focus on Culture and Risk. International Federation of Red Cross and Red Crescent Societies, Geneva.Mallet, R. (1862) Great Napolitan Earthquake of 1857: The First Principles of Observational Seismology. 2 Volumes, Chapman and Hall, London.

Moustafa, K. (2015) 'The disaster of the impact factor'. Science and Engineering Ethics. 21(1). pp. 139-142.

Obokata, H., T. Wakayama, Y. Sasai, K. Kojima, M.P. Vacanti, H. Niwa, M. Yamato, and C.A. Vacanti (2014) 'Retraction: stimulus-triggered fate conversion of somatic cells into pluripotency'. Nature. 511(7507). pp. 112.

Prince, S. (1920) Catastrophe and Social Change: Based Upon a Sociological Study of the Halifax Disaster. Studies in History, Economics and Public Law No. 94, Colombia University Press, New York.

Quarantelli, E.L. (1997) 'Problematical aspects of the information/communication revolution for disaster planning and research: ten non-technical issues and questions'. Disaster Prevention and Management. 6(2). pp. 94-106.

Schiltz, M. (2018) 'Science without publication paywalls: cOAlition S for the Realisation of 
Full and Immediate Open Access'. PLOS Medicine. 15(9). pp. e1002663. https://doi.org/10.1371/journal.pmed.1002663 (last accessed on 4 October 2019).

Shaw, C. (2013) 'Elsevier buys Mendeley: your reaction'. The Guardian. 10 April. https://www.theguardian.com/higher-education-network/blog/2013/apr/10/elsevierbuys-mendeley-academic-reaction (last accessed on 26 January 2019).

Van Noorden (2017) 'The science that's never been cited'. Nature. 552(7684). pp. 162-164.

Verbeek, R.D.M. (1884) ‘The Krakatoa eruption'. Nature. 30(757). pp. 10-15.

Verbeek, R.D.M. (1886) Krakatau. Imprimerie de l'Etat, Batavia.

Weller, A.C. (2001) Editorial Peer Review: Its Strengths and Weaknesses. ASIST Monograph Series, American Society for Information Science and Technology, Information Today Inc., Medford.

White, G.F. (1936) 'Notes on flood protection and land-use planning'. Planners Journal. 3(3). pp. 57-61.

White, G.F. (1945) Human Adjustment to Floods. Research paper No. 29, University of Chicago Department of Geography, Chicago.

Wilsdon, J., L. Allen, E. Belfiore, P. Campbell, S. Curry, S. Hill, R. Jones, R. Kain, S. Kerridge, M. Thelwall, J. Tinkler, I. Viney, P. Wouters, J. Hill, and B. Johnson (2015) The Metric Tide: Report of the Independent Review of the Role of Metrics in Research Assessment and Management. Higher Education Funding Council for England, Bristol.

Wisner, B. (2017) 'Science matters! A reflection on the first issue of Disasters'. Disasters. 40th Anniversary Virtual Issue. doi:10.1111/disa.12254

Wisner, B., J.C. Gaillard J.C. and I. Kelman (eds.) (2015) Disaster Risk. 4 Volumes, Major Work Series, Routledge, London.

Zudilova-Seinstra, E. (2013) Designing the article of the future. www.elsevier.com/connect/designing-the-article-of-the-future (last accessed on 4 October 2019).

\footnotetext{
i See, for example, Disasters virtual special issues: https://onlinelibrary.wiley.com/page/journal/14677717/homepage/virtualissuespage.html or those of the International Journal of Disaster Risk Reduction: https://www.sciencedirect.com/journal/international-journal-of-disaster-risk-reduction/special-issues
} 